\title{
Técnicas territoriales para la apropiación del bosque seco peruano: El caso de los comuneros de Catacaos frente al avance de la agroindustria en un contexto de emergencia humanitaria
}

Territorial Techniques for Controling the Peruvian Dry

Forest: Catacaos Peasantries Facing the Expansion of Agribusiness During a Humanitarian Emergency

Técnicas territoriais para a apropriação do Bosque Seco peruano: o caso dos comuneiros de Catacaos frente ao avanço da agroindústria em um contexto de emergência humanitária

María Luisa Burneo*

Recibido: 7 de marzo de 2019

Aprobado: 10 de octubre de 2019

Doi: https://www.doi.org/10.12804/revistas.urosario.edu.co/territorios/a.7736

\section{Para citar este artículo:}

Burneo, M. L. (2020). Técnicas territoriales para la apropiación del bosque seco peruano: El caso de los comuneros de Catacaos frente al avance de la agroindustria en un contexto de emergencia humanitaria. $\mathrm{Te}^{-}$ rritorios, (42-Especial), 1-29. https://www.doi.org/10.12804/revistas.urosario.edu.co/territorios/a.7736
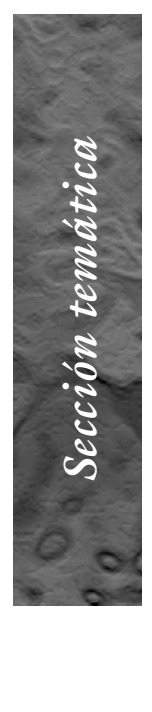
Palabras clave

Comunidades

campesinas,

acaparamiento de tierras, reasentamiento de poblaciones,

gobierno comunal, técnicas territoriales, agroindustrias.

Keywords

Peasant communities, land grabbing, population resettlements, communal government, territorial techniques, agribusiness.

Palavras-chave

Comunidades camponesas, monopolização de terras, reassentamento de populações, governo comunal, técnicas territoriais, agroindústrias.

\section{tersitarios 42-Especial}

RESUMEN

El artículo analiza las nuevas ocupaciones en tierras comunales del bosque seco de la costa norte peruana, en el contexto del desplazamiento forzado de familias comuneras debido a recientes fenómenos climáticos. Las comunidades del bosque seco tienen una historia que se remonta al siglo XVI y poseen derechos consuetudinarios sobre miles de hectáreas. Sin embargo, en la última década, el avance de empresas agroindustriales sobre estos territorios ha generado nuevas disputas. A partir del estudio de caso de la comunidad campesina de Catacaos y en base a un trabajo de campo que recoge observaciones y entrevistas en profundidad realizadas en diversos periodos entre los años 2013 y 2018 , se muestran las técnicas territoriales desplegadas por las empresas para apropiarse de tierras comunales, así como el surgimiento de nuevas narrativas entre las familias comuneras, que buscan legitimar la negociación con la agroindustria y evidencian una pérdida progresiva de control comunal del territorio.

\section{ABSTRACT}

This paper analyzes the new land occupations of the common land located in the dry forest, over the northern Peruvian coast, in the context of forced displacement due to extreme climatic events and severe flooding. Peruvian peasant communities in the area go back to the sixteenth century, having customary rights over thousands of acres. However, over the last decade, agribusinesses have expanded their industry over communal land, creating new conflicts. Through ethnographic fieldwork, observations, and in-depth interviews between the years 2013 and 2018 , this paper analyzes the case study of the peasant community of Catacaos. It presents the different territorial techniques used by the agribusiness for taking control over common lands, as well as emergent new narratives amongst local families looking to legitimize negotiations with private actors, showing the progressive loss of control over common lands and communal territory.

\section{RESUMO}

O presente artigo analisa as novas ocupações em terras comunais do Bosque seco da costa norte peruana, no contexto do deslocamento forçado de famílias comuneiras devido a fenômenos climáticos recentes. As comunidades do Bosque seco têm uma história que remonta ao século XVI e possui direitos consuetudinários sobre milhares de hectares. No entanto, na última década, o avanço de empresas agroindustriais sobre estes territórios tem gerado novas disputas. A partir do estudo de caso da comunidade camponesa de Catacaos, e com base em um trabalho de campo que recolhe observações e entrevistas em profundidade realizadas em diversos períodos entre os anos 2013 e 2018, o artigo mostra as técnicas territoriais desenvolvidas pelas empresas para se apropriar de terras comunais, assim como o surgimento de novas narrativas entre as famílias comuneiras, que buscam legitimar a negociação com a agroindústria e evidenciam uma perda progressiva de controle comunal do território. 


\section{Introducción}

Los procesos de concentración de tierra, la expansión de fronteras agrícolas y los nuevos cultivos agroindustriales dan la hora en el debate sobre territorios rurales en Perú y América del Sur, en general. Distintas entradas teóricas que retoman la discusión sobre bienes comunes (Ostrom, 1990), nuevas formas de gobernanza (Mazurek, 2009; Bebbington, 2013) y desigualdades interdependientes (Göbel, 2015; Göbel, Góngora \& Ulloa, 2014) sirven como marco de referencia para este debate. En este amplio marco, la discusión sobre comunidades indígenas y campesinas ha vuelto a tomar fuerza en el Perú, luego de casi tres décadas en las que estas habían sido parcialmente dejadas de lado como sujeto de estudio, entre otras razones, por la centralidad de temas como la violencia armada interna y las migraciones campo-ciudad, pero también por haber sido desplazadas de las políticas y la agenda pública nacional (Pajuelo, 2000; Urrutia, 2003). Con el giro neoliberal peruano en la década de 1990, las comunidades fueron colocadas en el discurso oficial del Estado como opuestas a la modernización del campo; discurso que fue de la mano con un paquete de nuevas normas sobre derechos de propiedad comunal y manejo de recursos naturales en el país (Bebbington, 2007; Bury, 2007; Castillo, 2009). Además, el inicio de un nuevo ciclo extractivo en los años 2000 generó la explosión de cientos de conflictos socioambientales en el Perú, ${ }^{1}$ y con ello, muchos de los trabajos sobre ámbitos rurales viraron hacia el estudio de los conflictos entre comunidades y empresas extractivas, dejando de lado los estudios sobre gobierno comunal, tierras y territorio. Luego de dos décadas y de cara al avance de nuevos procesos como la concentración de tierras en manos de agroindustrias de caña de azúcar en la costa norte (Eguren, 2013) y de palma aceitera en la Amazonía (Dammert, 2016) surgen nuevos estudios sobre tierras y comunidades campesinas y nativas en el Perú (Diez, 2012; 2017; Burneo, 2013; 2016b; Dammert, 2016; Mesclier, Mamani \& Huamantingo, 2018; Huamán, 2018, entre otros).

Mientras en la sierra los procesos sobre concentración, cambios de uso y revalorización de la tierra están ligados a la expansión de la gran minería y se dan sobre comunidades campesinas alto-andinas, en la costa norte peruana tales procesos están vinculados a la industria petrolera y más recientemente a la agroindustria (Diez, 2012; Burneo \& Huamán, 2013; Eguren, 2013). Estos últimos se dan sobre el ecosistema costero llamado bosque seco de llanura, ${ }^{2}$ que se extiende desde el borde costero del océano Pacífico hasta los 250 m.s.n.m. y abarca un amplio territorio, dentro del cual se encuentran varios cientos de miles de hectáreas clasificadas por el Estado como eriazas. Muchas de ellas se encuentran, sin embargo, al interior de territorios de antiguas comunidades
${ }^{1}$ En el Perú, este fue llamado el boom extractivo y responde a la subida de los precios de los metales entre 2004 y 2012, principalmente. Los conflictos sociales en el Perú pasaron de 30 a más de 200 anuales según las cifras oficiales de la Defensoría del Pueblo.

${ }^{2}$ El bosque seco de llanura pertenece a la ecorregión del bosque seco tropical, ubicada al norte del Perú, que va desde el mar hasta los 1600 m.s.n.m., y limita con ecosistemas montañosos.

\section{territarias 42-Especial}

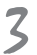


${ }^{3}$ En el Perú, las comunidades indigenas fueron reconocidas formalmente por la nación en la Constitución de 1920. En 1969, con la Ley de Reforma Agraria, se les cambió el nombre a campesinas debido, entre otras cosas, a la carga peyorativa que tenía en el Perú el término indigena (Remy, 2013). En 1987, se aprobó la Ley General de Comunidades Campesinas, que las define como: "organizaciones con existencia legal y personería juridica, integradas por familias que habitan y controlan determinados territorios, ligadas por vínculos ancestrales, sociales, económicos y culturales, expresados en la propiedad comunal de la tierra”. Actualmente, existen en el Perú 6277 comunidades campesinas (Cenagro, 2012). Estasinstituciones fueron reconocidas por el Estado peruano desde 1919. Algunas comunidades tienen su origen en las antiguas reducciones de indios, otras se formaron en procesos más recientes como durante la Reforma Agraria en la década de 1970 o luego de las tomas de tierra de la década de 1980, sobre todo, en el sur andino (Remy, 2013).

\section{territarios 42-Especial}

campesinas que reclaman territorios ancestrales (Diez, 2006; Mesclier \& Chaléard, 2006; Mesclier, Auquier \& Vaillant, 2014; Revezs, 1992; Burneo, 2016a). ${ }^{3}$

Por su antigüedad, historia y extensión, una de las comunidades más importantes del bosque seco de Piura es la comunidad San Juan Bautista de Catacaos (SJBC), caso en el que se centra este artículo. La comunidad SJBC, ubicada en el departamento de Piura, al norte del Perú, tiene su origen en la reducción de indios del pueblo de Catacaos del siglo XVI (Cruz Villegas, 1982), ${ }^{4}$ que fue inscrita formalmente como comunidad en el Registro de Comunidades Indígenas en 1940. Su territorio ancestral abarcaba más de 200 mil hectáreas del bosque seco, las cuales se fueron reduciendo - por procesos de despojo, expansión de haciendas, privatización y venta ilegal, entre otros-, a lo largo de los siglos (Revesz, 1992; Diez 2017). Esta comunidad cuenta con alrededor de 20000 comuneros inscritos en el padrón oficial, que habitan en los más de 100 caseríos rurales que la conforman. ${ }^{5}$ Su órgano de gobierno es la Asamblea General de Comuneros, representada por una Directiva Comunal que se elige cada dos años, de acuerdo con la Ley General de Comunidades Campesinas promulgada en 1987 (figura 1).

A lo largo de su historia, la costa de Piura ha sufrido el impacto de diversos fenómenos climáticos. Por ejemplo, el río Piura y su cauce variable han generado numerosos desplazamientos de los cuales se tiene información desde tiempos de la colonia (Cruz, 1982; Revesz, 1992; Zapata, 2002; Diez 2017). Estos territorios, por tanto, se han conformado en distintos momentos de apropiación y desplazamientos en el bosque seco, según un movimiento que dialoga con las crecidas del río Piura. El momento de la historia comunal que analizaré a continuación se inscribe en un escenario particular: los nuevos desplazamientos de poblaciones provocados por el desborde del río Piura en el año 2017, que arrasó caseríos enteros dentro del ámbito de la comunidad SJBC. El desborde del río fue generado por un fenómeno climático llamado El Niño Costero, que produjo lluvias anómalas, que causaron inundaciones y derrumbes en varias zonas de la costa y sierra peruanas.

A partir del contexto descrito, este artículo discute las siguientes preguntas: ¡cómo se viene dando el proceso de expansión de agroindustrias en las tierras de la costa y qué implicancias tiene en la configuración de los territorios comunales? ¿Qué nuevas formas de apropiación del espacio despliegan los comuneros en este proceso para reivindicar sus derechos sobre la tierra? ¿Qué técnicas despliegan los empresarios para asegurarse el control de las tierras sobre las que se han asentado? ¿Qué nuevas narrativas territoriales surgen desde los comuneros y sus líderes en este contexto? Recogiendo estas preguntas, el presente artículo analiza el proceso de reasentamiento y las nuevas formas de apropiación del bosque seco por parte 
Figura 1. Mapa de Perú, departamento de Piura y distritos de Catacaos y Curamori

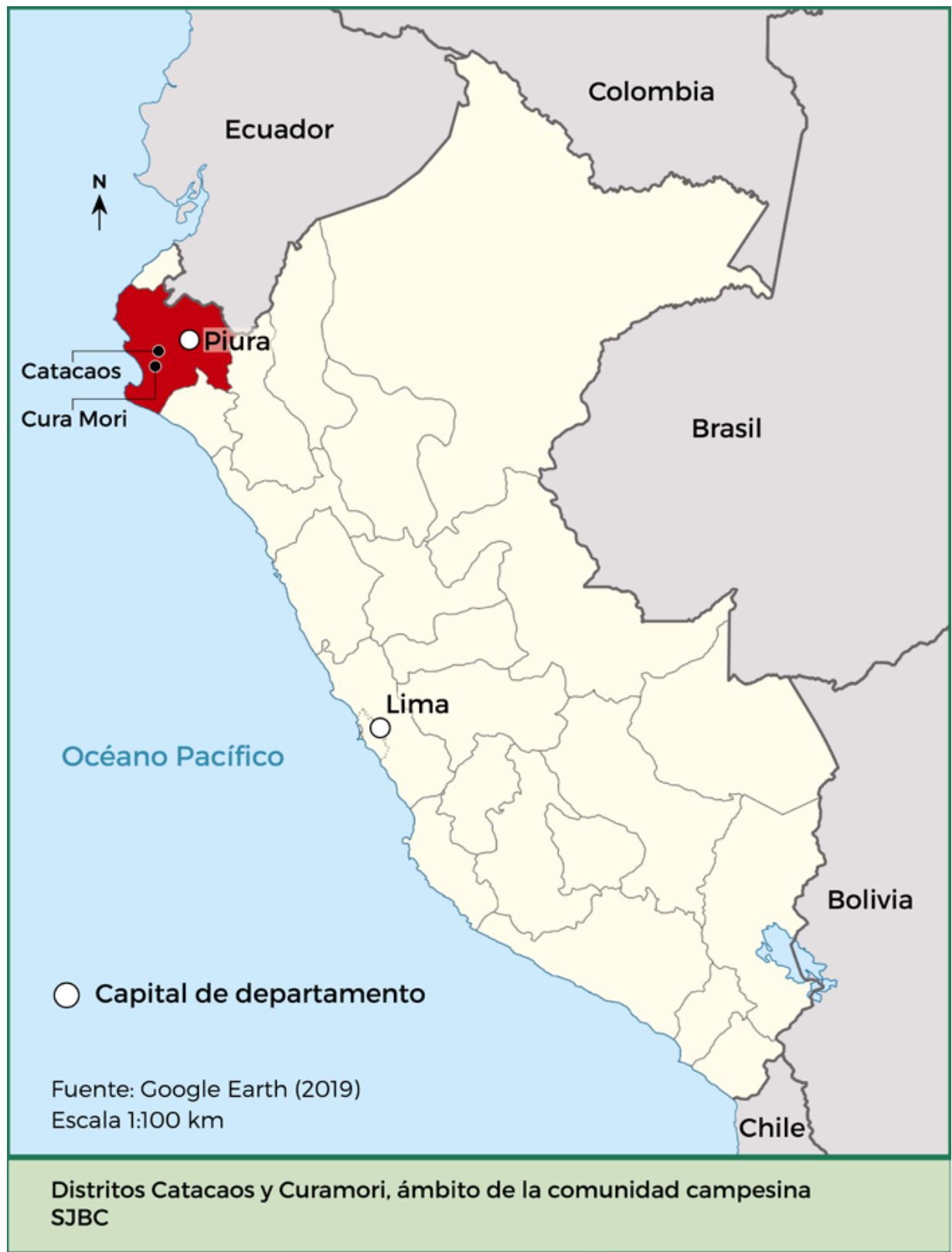

$\Longleftarrow$

${ }^{4}$ Catacaos es uno de los cinco distritos del Bajo Piura que se superponen al ámbito de la comunidad SJBC. Su origen se remonta a 1547 , año en que se construyó el templo católico San Juan Bautista de Catacaos en tierras de los curacazgos de la etnia tallán. Durante la colonia, Catacaos fue la parroquia del pueblo de reducción de indios. Luego de la independencia, en 1825, Catacaos fue reconocido como distrito por decreto de Simón Bolívar. Actualmente cuenta con 75870 habitantes.

5 Caserio es el término utilizado para referirse a centros poblados rurales, habitados con ánimo de permanencia, que no tienen la categoría de municipio de centro poblado.

\section{tersitarios 42-Especial}


${ }^{6}$ Quiero agradecer a la antropóloga Alejandra Cáceres, con quien realizamos dos visitas a los nuevos asentamientos durante los años 2016 y 2017, y por su colaboración con la actualización de información de campo para el año 2018.

${ }^{7}$ El territorio de la comunidad SJBC se extiende sobre cinco distritos de Piura, entre ellos, los distritos de Catacaos y Cura Mori, en los que se focaliza nuestro estudio.

${ }^{8}$ El Censo Nacional Agropecuario 2012 (el último realizado en Perú) arroja para Piura que el 61,9\% de unidades agropecuarias tiene menos de 1,9 hectáreas $y$ el $84,16 \%$, menos de 4 . El tamaño de las parcelas familiares en la comunidad se estima a partir de observaciones realizadasen varios trabajos de campo (2013 al 2017) y de la revisión de los padrones de usuarios de la Comisión de Regantes de Cura Mori, perteneciente a la Junta de Regantes del Bajo Piura.

\section{territorias 42-Especial}

de las familias comuneras en el contexto de la emergencia humanitaria generada por el desborde del río Piura. En medio de un escenario de gran incertidumbre se recurre a antiguas lógicas comunales, pero también a nuevas técnicas territoriales.

Los hallazgos presentados en este artículo se basan en visitas y entrevistas en profundidad realizadas a comuneros hombres y mujeres del caserío de Santa Rosa de Cura Mori - perteneciente al ámbito de la comunidad SBJC y uno de los más devastados por la emergencia climática-, así como a directivos de SJBC en el año 2016, y luego del desastre ocurrido en el mes de marzo de 2017. 6 Sin embargo, recoge y considera información obtenida en trabajos de campo previos realizados por la autora como parte del terreno para su tesis doctoral, entre los años 2013 y 2016. Tales hallazgos apuntan a mostrar que la presencia de la agroindustria en las tierras comunales del bosque seco implica un conjunto de técnicas territoriales que se enfrentan a las estrategias comunales de ocupación del territorio, pero que a la vez activan nuevos dispositivos y nuevas narrativas en un contexto de alta vulnerabilidad de las familias comuneras debido a la emergencia humanitaria.

\section{Perspectiva teórica y breve historia de un territorio en movimiento}

El bosque seco se caracteriza por vegetación de hojas pequeñas, arbustos espinosos y árboles como el sapote y el algarrobo, del cual se desprenden las vainas que son alimento de cabras y de las que se extrae la miel de algarrobina. Las temperaturas oscilan entre los 20 y los 40 grados centígrados, dependiendo de la época del año, con fuertes lluvias estacionales entre enero y abril. Los territorios comunales se superponen a distritos urbanos y abarcan a cientos de pequeños caseríos rurales. ${ }^{7}$ Las familias se dedican principalmente a la pequeña agricultura en las áreas irrigadas, sembrando cultivos de panllevar - como frijol y maíz-, así como algodón, dependiendo de la disponibilidad de agua de cada campaña. Una unidad agropecuaria promedio puede tener entre 3 y 1 hectárea, pero las tierras están dispersas en distintas parcelas (llamadas chacras) y no todas están sembradas debido a la falta de agua y de acceso a créditos. ${ }^{8}$ Así, por lo general, las familias comuneras tienen parcelas muy pequeñas que fluctúan entre 1 y 0,10 hectáreas. Algunas pocas familias tienen ganado vacuno en pequeñas cantidades (alrededor de diez cabezas) y casi todas tienen animales de corral para el autoconsumo o la venta eventual en el mercado local o entre vecinos. Por ello, las familias son pluriactivas y combinan la actividad agrícola con el pequeño comercio (venta de abarrotes, pescado o artesanías) y trabajos temporales, en su mayoría informales, en las ciudades cercanas (obreros de construcción, choferes de moto-taxi y peones agrícolas, entre otros). Si bien estas conducen sus parcelas de manera 
individual, reconocen que se encuentran dentro del territorio de la comunidad SJBC, que es la propietaria de las tierras.

Para referirme al territorio comunal retomaré la idea planteada por Escobar (2014), según la cual un territorio se constituye, además del espacio físico y los ecosistemas, a partir de procesos de territorialización que llevan a la construcción de identidades y diversas formas de apropiación del espacio y los recursos. De esta manera, el territorio es en sí mismo un proyecto de vida que contiene un pasado compartido y que, al mismo tiempo, implica un futuro común. En el caso del territorio de las comunidades indígenas/ campesinas del bosque seco, este se ha ido construyendo en movimientos constantes entre el valle y el desierto debido a las crecidas del río Piura (Revesz, Aldana, Hurtado \& Requena, 1996), dibujando zonas diferenciadas entre las parcelas agrícolas - de tenencia familiar-y las extensas zonas conocidas como el descampado ${ }^{9}$ - de uso común-. El estudioso de la región Piura, Bruno Revesz (1992), relata las inundaciones de los años 1871 , 1925 y 1983 en las que da cuenta de su poder para transformar el paisaje y el territorio comunal:

no es solamente la magnitud del caudal del río y la posibilidad de su desborde lo que está en juego, sino la violencia acumulativa de lluvias torrenciales que meses tras meses trastornan el relieve, develan en aparentes planicies, quebradas olvidadas, derrumban paredes y casas de adobe, borran caminos, interrumpen actividades, mientras que las plagas abundan y la incertidumbre se instala (p. 84).

Como relata Revesz (1992), a lo largo de siglos, los comuneros de Catacaos han convivido con las fluctuaciones del río Piura. Así, frente a las recurrentes crecidas en la época de lluvia, entre enero y abril, las familias fueron moviéndose a zonas del territorio comunal, distantes del río y con una ligera elevación, para luego volver a los pequeños caseríos abandonados. En algunos pocos casos, se formaron nuevos caseríos en medio del desierto que se convirtieron en asentamientos permanentes, como ocurrió luego del devastador fenómeno del Niño de 1983, que recibieron nombres como Paraíso y Arca de Noé. Algunas familias desarrollaron estrategias de doble residencia entre los antiguos y nuevos asentamientos, mientras otras se trasladaron permanentemente, manteniendo, a pesar de ello, fuertes lazos basados en el parentesco y el intercambio ritual -a través, por ejemplo, de las fiestas de los santos católicos patronos de cada localidad- (Revesz, 1992). Luego de otro fuerte Niño en 1998, la tendencia fue buscar zonas de desplazamiento hacia tierras comunales no ocupadas del descampado, más cercanas a la carretera Panamericana, que conecta las principales ciudades costeras.

Además de los agricultores, los grupos de ganaderos de cabras del desierto
${ }^{9}$ En el lugar se utiliza el término para referirse a las zonas del bosque seco, al interior del territorio comunal, también llamadas "El Desierto", donde no hay parcelas cultivadas, ningún tipo de infraestructura ni servicios. territarios 42-Especial 
${ }^{10}$ En este caso nos referimos a la comunidad SJBC, pero lo mismo sucede con las grandes comunidades del bosque seco cuyos territorios ancestrales suman más de un millón de hectáreas, como San Martín de Sechura (Diez, 2017), San Lucas de Colán (Burneo, 2016b) o Santo Domingo de Olmos (Mesclier, Auquier \& Vaillant, 2014), vecinas de Catacaos. No sucede lo mismo en el caso de las comunidades campesinas de la sierra, muchas de las cuales poseen entre $5000 y$ 10000 bectáreas (Cenagro, 2012) y tienen un mayor control territorial.

\section{territorias 42-Especial}

se mueven a lo largo de las grandes extensiones del territorio comunal aprovechando los recursos del bosque seco, como los algarrobos para el alimento del ganado, pero también para la extracción de miel de algarrobina - que se vende en ciudades cercanas - y de madera - fundamentalmente leña para cocinar- (Diez, 2017; Perevolotski, 1991). Esta forma de apropiación del bosque seco, que implica movilidad y conocimiento de normas sociales de uso compartido del descampado, es muy antigua entre los comuneros de Catacaos. Combina el conocimiento físico de zonas diferenciadas al interior de un vasto espacio con el reconocimiento de la existencia de una jurisdicción comunal sobre un territorio que, si bien usan como propio, en última instancia le pertenece a la comunidad, considerada "la madre de las tierras". Estas zonas diferenciadas suponen la existencia de más de una figura o nivel de apropiación (Le Roy, 2011), que va desde la posesión individual de las parcelas cultivadas, sobre las cuales los llamados comuneros históricos — que recibieron las tierras en herencia de sus antepasados - tienen un alto sentido de pertenencia cercano a la propiedad, hasta el uso compartido del bosque seco para extraer madera de los algarrobos y sapotes. Tomando la propuesta de Le Roy (2011), se puede decir que existen conocimientos que diferencian un conjunto de paquetes distintos de derechos y regímenes de apropiación con sus variantes de acceso, uso y circulación, y los mecanismos para llevarlos a la práctica. Todo este conjunto de conocimientos y prácticas constituyen saberes territoriales construidos a lo largo de la historia del territorio comunal de Catacaos.

\section{El territorio comunal como construcción histórica}

Puede considerarse que los espacios del descampado dentro de los territorios comunales del bosque seco son espacios comunes o de bienes comunes (Ostrom, 1990). La paradoja es tal vez que se trata de recursos que han sido aprovechados a lo largo del tiempo sin mayores exclusiones o rivalidades entre grupos de familias —usando los términos de la misma autora- a pesar de que la comunidad no siempre ha tenido la capacidad de control efectivo del conjunto del territorio comunal. ${ }^{10}$ La capacidad de crear normas sociales que regulan el acceso y uso del bosque seco se vincula más bien a la historia de la comunidad SJBC, construida sobre narrativas de defensa de la tierra frente al avance de las haciendas en el siglo XIX y otros agentes privados a lo largo del siglo Xx. Alejandro Diez (2017), en un trabajo sobre los pueblos de reducción de indios de Sechura y Catacaos, recoge la historia de esta en el siglo XVI, que agrupa población de la etnia tallán y de la formación de estas comunidades indígenas. Diez señala que, además de las compras de tierra a la corona española en el siglo XVI, las comunidades del Bosque Seco lograron 
apropiarse de un vasto territorio y legitimarlo como suyo utilizando un conjunto de estrategias como la posesión a lo largo de los siglos XVIII y XIX, ${ }^{11}$ pero también acogiéndose a procesos colectivos como la toma de tierra contra las haciendas a lo largo del siglo xx y, posteriormente, a la formación de nuevas organizaciones comunales durante la Reforma Agraria (1969-1975). ${ }^{12}$ Es decir, construyendo una memoria basada en la defensa de la tierra y la apropiación del territorio bajo la tutela de la comunidad.

Las haciendas, que en la zona eran fundamentalmente algodoneras, fueron expropiadas por el aparato de la Reforma Agraria -implementada por el gobierno revolucionario de las fuerzas armadas- y adjudicadas a la comunidad bajo la forma de Cooperativas Comunales de Producción (CCP). Los beneficiarios directos serían los expeones de las haciendas, pero en tanto a tierras devueltas a la comunidad, estos debieron inscribirse como comuneros para poder ser socios de las $\mathrm{CCP}$, aumentando así la masa comunera que hasta el momento estaba conformada solo por los autodenominados comuneros históricos. En la misma época, durante la década de 1970, la comunidad formó las Unidades Comunales de Producción (UCP) en base a tierras marginales no ocupadas, que destinó a quienes no habían sido beneficiarios de la Reforma. Como ha estudiado Castillo (1991), las UCP del desierto constituyeron un proyecto colectivo comunal que permitió la cesión de tierras de la comunidad a los comuneros sin tierras, por decisión de la Asamblea general de Comuneros. Ello otorgó mayor legitimidad a la comunidad y fortaleció su presencia en el territorio. Así, la lucha por la recuperación de tierras y la formación de CCP y UCP fijaron hitos clave en la historia comunal cataquense y constituyen parte de la identidad comunera (van der Ploeg, 2006; Diez, 2012; Burneo, 2013).

Años después, hacia la segunda mitad de la década de 1980, las CCP y las UCP enfrentaron una serie de problemas financieros y de gestión luego del devastador fenómeno de El Niño de 1983 y la caída del precio del algodón (1985-1990). Posteriormente, con el viraje neoliberal del régimen de Alberto Fujimori (1990-2000) y sus efectos sobre la política agraria, las tierras se parcelaron y las lógicas de gestión colectiva fueron progresivamente desplazadas por lógicas individuales (Burneo, 2013; Diez, 2017). Este giro neoliberal se consolidó con la nueva Constitución de 1993, que derivó en acciones como el cierre del Banco Agrario y la liberación del mercado de tierras comunales, que permitieron la parcelación y venta de estas, las cuales habían sido consideradas inalienables e inembargables en todas las constituciones previas. Asimismo, el Proyecto Especial de Titulación de Tierras financiado por el BID, promovió en su primera etapa (1994-2000) una política de titulación de predios individuales al interior de territorios comunales, muchos de los cuales, como el de la comunidad
${ }^{11}$ La posesión familiar es una figura largamente extendida y reconocida como legítima en el conjunto de comunidades, que implica ocupary darle un uso continuo a la tierra, que en este caso responde a la pequeña agricultura y la ganadería familiar.

${ }^{12}$ A lo largo del siglo $X X$, antes de la Reforma Agraria de 1969, SJBC y otras comunidades de Piura $y$ del pais en general se habian enfrentado en diversas ocasiones a las haciendas en propiedad de terratenientes, que avanzaban sobre tierras comunales, despojando a las familias de sus parcelas (Burga \& Manrique, 1990). Las haciendas tenian una extensión muy variable y podian fluctuar entre propiedades de unas 200 a más de 100000 hectáreas, como el caso de la hacienda Casa Grande en la costa peruana con 107000 (Matos \& Mejia, 1980). A lo largo de años, las comunidades se organizaban para "tomar" $y$ recuperar las tierras que les habian sido despojadas. Finalmente, la Reforma Agraria de Velasco Alvarado (1969-1975) expropió a los hacendados y entregó las tierras a los exfeudatariosy

territarios 42-Especial 
$\Leftarrow$

peones de hacienda bajo la figura de empresas asociativasestatales - cooperativas agrarias de producción y otras formas- (Eguren, 2009).

\section{territorias 42-Especial}

SJBC, solo contaban con antiguos títulos y documentos coloniales mas no con un título del conjunto del territorio saneado e inscrito en los registros públicos. Retomaré este punto más adelante.

Por todo lo anterior, Diez (2017) propone la idea de la existencia de una "jurisdicción territorial” más que de propiedad comunal, y señala que, en las últimas décadas, debido a procesos de urbanización, a la injerencia de otras instituciones con poder sobre el territorio - como las municipalidades distritales - y a la presión de agentes privados, las tierras comunales del bosque seco se han convertido en un híbrido entre bienes colectivos (intercomunales) y bienes semipúblicos. Con ello, la noción de la jurisdicción territorial construida en base a la historia de formación de la comunidad como "madre de las tierras" y de la defensa del territorio, se debilita progresivamente. Esta idea aún se sostiene (y circula) entre las generaciones de comuneros mayores (entre los 90 y 60 años), los cuales fueron parte de las luchas por la recuperación de tierras comunales en manos de los hacendados en décadas pasadas o vivieron las épocas fuertes de la organización comunal en los años 80. Pero estas generaciones se están extinguiendo y, con ellas, las viejas narrativas sobre la comunidad y la legitimidad de su territorio ancestral. Aunque con matices distintos, un proceso similar ocurre en otras zonas del bosque seco, como en la comunidad vecina, en donde una empresa privada extrae petróleo hace más de una década (Burneo \& Huamán, 2013; Burneo, 2016b) y la agroindustria de caña para producción de etanol controla importantes zonas del valle (Huamán, 2018).

\section{Debilitamiento de la comunidad y llegada de nuevos inversionistas}

Al igual que otros ámbitos del país, desde la década de 1990, la comunidad ha venido perdiendo fuerza como organización y se ha visto deslegitimada en su función de defensa del territorio, frente a la presencia de nuevos agentes de poder local y a su exclusión de las políticas públicas. Asimismo, en el contexto de concentración de tierras en el Perú (Eguren, 2013), los problemas de la falta de titulación comunal de los años noventa adquieren una relevancia mayor en un escenario de mayor vulnerabilidad jurídica frente a quienes los comuneros llaman "los nuevos dueños de la tierra". Ello tiene efectos concretos en la vida de las familias comuneras y es justamente lo que viene sucediendo en el caso de uno de los caseríos rurales más antiguos que conforman la comunidad SJBC, el caserío San Rosa de Cura Mori, conformado por alrededor de 350 familias (Directorio Nacional de Centros Poblados, 2017).

Los moradores de Santa Rosa recuerdan cómo en las inundaciones de 1998, la comunidad los acogió y alimentó en su local comunal, donde acamparon durante un mes. Asimismo, esta aceptó cederles nuevas tierras a los diversos caseríos en 
situación de vulnerabilidad por su cercanía al río, para una futura reubicación. En el año 2006, ello se formalizó con la entrega de un certificado comunal que otorgaba el derecho de posesión de una importante zona del desierto a la recién conformada Asociación de Moradores del Caserío de Santa Rosa de Cura Mori. Estas tierras se encuentran a unos 12 kilómetros del antiguo caserío y muy cerca de la carretera Panamericana Norte. Ello es relevante, pues constituye un mecanismo que refuerza el nexo con la comunidad como instancia legítima de regulación del territorio y acceso a tierras. Sin embargo, dada la carencia de recursos económicos y la falta de apoyo estatal para acondicionar el terreno, pasaron los años y la toma de posesión de las nuevas tierras del desierto nunca se hizo efectiva. Como señalan los comuneros de Santa Rosa: "como no pudimos lograr financiamiento, las teníamos ahí las tierras, para el futuro, para nuestros hijos o para un nuevo desborde del río". ${ }^{13}$

Hacia el año 2013, los comuneros de Santa Rosa se percataron de la presencia de una empresa de uva que se había instalado en tierras comunales (figura 2), incluyendo parte de las tierras que la comunidad les había cedido "para el futuro", por 1998, luego de las terribles inundaciones de aquel verano. Frente a ello, decidieron iniciar el proceso de toma de posesión, colocando pequeñas chozas de paja, ${ }^{14}$ con lo que anunciaron su presencia a la empresa. Como se ha señalado, una de las formas más antiguas de apropiación territorial de la comunidad consiste en lo que los comuneros llaman "tomar posesión". Para ello, deben demostrar que están usando estas tierras, aunque no sea para uso agrícola y deben gozar del reconocimiento de la comunidad. ${ }^{15}$ Mientras la empresa avanzaba instalando cultivos, se mantuvo una tensa situación entre esta y los comuneros de Santa Rosa. En el año 2015, la agroindustria construyó un cerco vivo e invadió una parte de las tierras de los comuneros de Santa Rosa — "la franja de tierras" — lo que disgusto a estos últimos, quienes quemaron el cerco vivo. Ello ocasionó un enfrentamiento con el personal de seguridad de la empresa, luego de lo cual tres jóvenes dirigentes de Santa Rosa fueron denunciados por agresión física. La policía, que fue enviada por el gobierno regional de Piura, actuó a favor de la empresa, dejando como saldo un comunero muerto.

Poco a poco, los moradores de Santa Rosa se dieron cuenta de que este no era el único caso de ocupación de tierras de la comunidad SJBC por parte de privados. Comuneros de diversos caseríos ya se habían percatado del avance de empresas privadas (agroindustrias e inmobiliarias) sobre otras zonas del bosque seco. Frente a ello, en el año 2015, los comuneros de varios caseríos del distrito de Cura Mori se organizaron en el Frente de Defensa de las Tierras de Cura Mori, para "defender de los nuevos gamonales las tierras que les había entregado la comunidad". ${ }^{16} \mathrm{El}$ Frente, en coordinación con la directiva
13 Entrevista a la presidenta de la asociación de moradores de Santa Rosa de Cura Mori (2016). Por su seguridad, el nombre ba sido omitido.

${ }^{14}$ Las chozas son pequeñas viviendas precarias hechas con carrizo y paja. Muchas veces se usan como marcas en el espacio y anuncian una futura ocupación.

${ }^{15}$ El proceso de toma de posesión debe ser considerado legitimo por el resto de los comuneros, ello implica contar con el respaldo de la comunidad a nivel de la Directiva Comunal - con un acta de entrega en posesión-y la probación en Asamblea General. En este caso, ambos procesos se babian llevado a cabo en 1998 y 2006.

${ }^{16}$ El Frente de Defensa es Autónomo si bien está conformado por comuneros de la comunidad de Catacaos, no es parte de su estructura formal. Es cercano a ella por su posición de defensa de las tierras comunales frente al avance de las agroindustrias. La expresión citada fue recogida en una entrevista realizada al comunero y presidente del Frente de Defensa en octubre de 2016.

\section{territarias 42-Especial}


${ }^{17}$ Las afirmaciones realizadas en este párrafo sobre la empresa, la asociación de moradores y el Frente de Defensa de las tierras se basa, por un lado, en entrevistas a profundidad realizadas a la presidenta de la asociación de moradores, al principal lider de Nuevo Santa Rosa y al presidente del Frente de Defensa. $\Upsilon$, por otro lado, en un conjunto de observaciones y conversaciones informales sostenidas con comuneros $y$ comuneras en 2016 en el caserio de Santa Rosa de Cura Mori, asi como una reunión sostenida con la Junta Directiva en la sede oficial de la comunidad campesina, en el pueblo de Catacaos. Los nombres han sido omitidos por protección de los entrevistados.

\section{territarias 42-Especial}

Figura 2. Agroindustria en expansión, colindante con las tierras comunales para futuros asentamientos entregadas a moradores de Santa Rosa

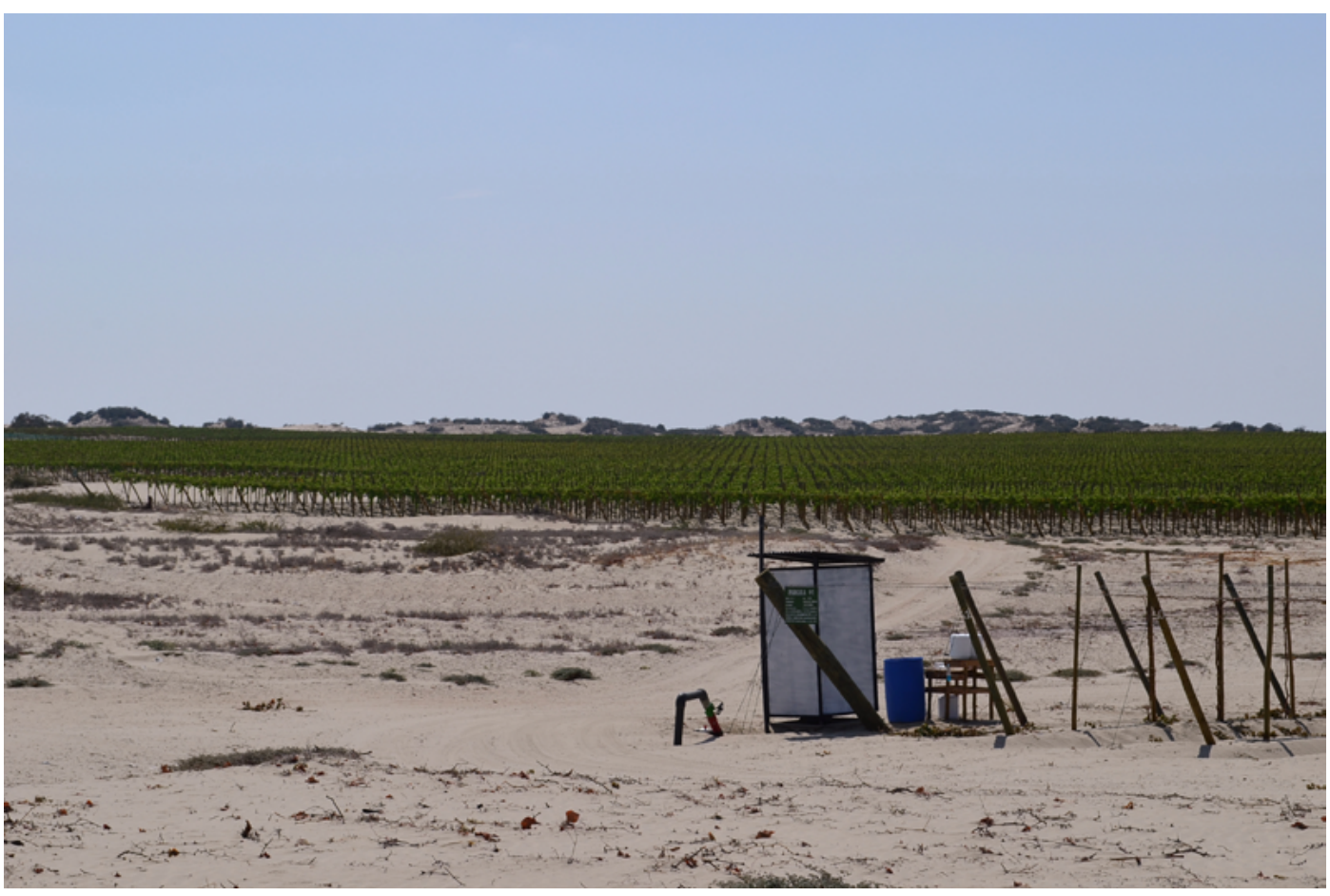

Foto: M. Burneo, octubre de 2016

central de la comunidad SJBC, organizó dos movilizaciones y un bloqueo de carretera para llamar la atención del gobierno regional. Sin embargo, las autoridades regionales no solo no respondieron a sus peticiones, sino que les solicitaron el título de propiedad de la zona (con inscripción en registros públicos) con el que la comunidad y los comuneros no cuentan. Sin el título, el gobierno regional los acusó de estar usurpando tierras, cerrando así cualquier posibilidad de negociación. El
Frente, poco a poco fue perdiendo fuerza, hasta quedar prácticamente inactivo. ${ }^{17}$

Hasta este punto, el escenario previo al desborde del río en el año 2017 muestra un espacio comunal, cuya legitimidad se ha construido a lo largo de una extensa historia de lucha por la defensa del territorio, pero que en el contexto de la presión sobre recursos, se convierte en un espacio disputado sobre el que se superponen lógicas privadas y comunales. Como señala Diez (2017), son "espacios 
de propiedad colectiva que empiezan a enajenarse del control comunal y dejan en la práctica de ser bienes comunes" (p. 34). Por otro lado, los intentos de organización colectiva terminan fracasando debido a un conjunto de factores: i) la falta de capacidad de la comunidad para apoyarlos con acciones concretas - por falta de recursos económicos y fragilidad institucional-; ii) la falta de recursos de los comuneros para solventar procesos de catastro y saneamiento físico legal de las zonas entregadas en posesión por la comunidad; iii) la imposibilidad de avanzar negociaciones con el Estado ante la falta de un título de propiedad del territorio comunal inscrito en registros públicos; iv) las acciones de fuerza de las empresas en el terreno y las denuncias judiciales a los dirigentes, y, como veremos más adelante, v) las necesidades de extrema urgencia de una población que, tras la emergencia, requiere de agua para sobrevivir en el desierto.

\section{Emergencia humanitaria, precariedad institucional y despojo de tierras}

Como hemos visto, desde hace décadas los comuneros han avanzado sobre las tierras comunales del bosque seco de la costa de Piura, poniendo en práctica la figura de la posesión: ocupar el espacio a través de distintos usos. Es importante "estar ahí" para que el descampado se convierta en un espacio de vida. Este dispositivo se sostiene a la vez en el discurso que apela a los derechos ancestrales de la comunidad sobre el territorio, así como al derecho legítimo de sus comuneros para ocuparlo. Como expliqué anteriormente, las formas locales de apropiación del descampado tienen numerosos antecedentes y la historia de ocupación y movilidad estuvo siempre acompañada de un discurso de reivindicación sobre un vasto territorio que la comunidad reclama como suyo. En esta sección veremos cómo los nuevos desplazamientos ocurridos luego del desborde del río del 2017 vienen construyendo narrativas distintas que se alejan de aquel discurso de lucha y reivindicación comunera.

Los intentos de posesión de las tierras del descampado que tuvieron lugar desde el 2013, ante la llegada de la empresa de uva, desplegaron tres estrategias locales: i) la instalación de chozas que anunciaban el inicio de la construcción de futuras viviendas; ii) la conformación de la ronda campesina del caserío de Santa Rosa para vigilar las tierras todas las noches en el desierto (un grupo de 10 varones rondando cada noche), y iii) el desplazamiento de grupos de mujeres del caserío (organizadas por turnos) durante el día, tres veces por semana, para cocinar y pasar el día con la intención de "dejarse ver". Con ello, el descampado iría dejando de serlo para convertirse en un nuevo espacio de vida seguro por su lejanía del río, que pronto sería nombrado y apropiado. Estas estrategias funcionaron alrededor de dos años, territarios 42-Especial 
18 Existe una plataforma llamada Cecobosque (Central de Comunidades Campesinas del Bosque Seco), creada con el fin de defender los recursos de las comunidades y la mejora de las condiciones de vida de sus pobladores, que busca canalizar proyectos de cooperación internacional cuyos temas trasversales son la soberanía alimentaria y la conservación del medio ambiente. Sin embargo, Cecobosque tiene poco alcance a nivel de los caserios de la comunidad y no tuvo mayor intervención ni en el conflicto con la empresa de uva ni en la situación posterior al desborde del río.

\section{territorias 42-Especial}

pero cada vez de manera más esporádica. Ante la falta de recursos para acondicionar el terreno, el desgaste del ir y venir diario (unos 12 kilómetros), el tiempo invertido en desmedro del cuidado de la chacra y de los hijos y el gasto en el desplazamiento se fue instalando el desánimo entre las familias y el proceso de posesión no se consolidó. Los dirigentes de Santa Rosa, pese a su esfuerzo, tampoco lograron ningún apoyo concreto del Estado para viabilizar el traslado de las familias a un lugar que fuese mínimamente habitable.

Todo ello trascurría con una tensión latente, hasta que ocurrió lo que de alguna manera se sabía que pasaría. El día 7 de marzo de 2017, los comuneros de Santa Rosa amanecieron con la alerta del inminente desborde del río Piura: la cadena humana que habían formado desde las orillas del río - a un kilómetro del caserío - hasta el pequeño pueblo, se activó para dar aviso a la población. Era necesario salir cuanto antes, sin tiempo de rescatar ganado ni bienes materiales. Las aguas arrasaron las chacras cultivadas y el caserío, y en pocas horas los pobladores se vieron atrapados en el pequeño altillo de la Iglesia. El escuadrón de rescate de las fuerzas armadas evacuó a los pobladores en balsas y los trasladó a las tierras del descampado, que ellos asumían como suyas. Allí pasaron noches bajo la torrencial lluvia, sin cobijo alguno hasta que llegaron algunas carpas donadas por entidades privadas y otras por el gobierno regional. El desborde del río significó un punto de quiebre para las familias de Santa Rosa: muchas de ellas no volvieron al antiguo caserío y empezaron una nueva vida en el asentamiento en el desierto al que llamaron Nuevo Santa Rosa.

En este contexto, el desborde del río Piura del año 2017 generó una ocupación abrupta y sin planificación. De cierta for$\mathrm{ma}$, la antigua figura de la posesión como ocupación progresiva y como construcción de un espacio de vida se vio irrumpida por la emergencia. Quedaba así expuesta la frágil gobernanza del bosque seco, que se explica por una serie de carencias - Como el saneamiento físico de la propiedad de la comunidad-, pero también, por el efecto de procesos de más largo plazo - como el debilitamiento de la organización colectiva luego de tres décadas de políticas neoliberales que liberalizaron el mercado de tierras $-{ }^{18} \mathrm{y}$, finalmente, por la ausencia de una mayor institucionalidad para la gestión territorial del bosque seco por parte del mismo Estado. A todo ello se debe agregar la falta de políticas para la pequeña agricultura familiar (Zegarra 2003, Castillo 2009, Eguren 2004, del Castillo, Castillo \& Márquez, 2011), que ha generado una crisis con consecuencias como el abandono de una parte de las parcelas y la migración de jóvenes, hombres y mujeres, que ya no se autodefinen como comuneros y que han perdido su vínculo con la comunidad. 


\section{Antes y después del desborde del río: compras ilegítimas y despojo institucionalizado}

Hemos perdido todo, nos han dicho que las tierras de la comunidad tienen nuevos dueños, son empresarios, nos dicen usurpadores. Esto es horrible (...) estamos en medio de la nada. ${ }^{19}$

Fueron varios los caseríos de la comunidad SJBC devastados por el desborde del río. Sus pobladores, al igual que los de Santa Rosa, se trasladaron a zonas alejadas de él en el desierto y formaron asentamientos vecinos a Nuevo Santa Rosa. Estos fueron llamados por el Estado y la cooperación internacional: Albergues Temporales. Luego del desastre, al acercarse al gobierno regional a pedir ayuda, los representantes y dirigentes de los nuevos asentamientos fueron advertidos de que se encontraban usurpando propiedad privada de terceros. Dentro de este grupo de "nuevos dueños de la tierra", se encontraba incluida la empresa de uva con la que los moradores de Santa Rosa mantenían un conflicto desde años atrás (figura 3 ).

¿Cómo era ello posible si esas tierras son de la comunidad campesina y, técnicamente, no pueden ser transferidas a terceros no comuneros ni vendidas sin aprobación en la Asamblea Comunal? La explicación radica en que esta vía de apropiación privada de tierras comunales se da a partir de compras ilegales. El mecanismo es el siguiente: actas falsas de cesión de tierras son extendidas por algún mal directivo en favor de comuneros ficticios (o incluso ya fallecidos); luego, con firmas de notarios locales, las actas son convertidas en contratos de compraventa entre los falsos comuneros y terceros. Finalmente, estos contratos son inscritos en registros públicos por registradores corruptos, que resultan en títulos de propiedad individual a nombre de los nuevos dueños. Es importante puntualizar que lo anterior no sería posible sin el marco normativo que se desprende de la Constitución neoliberal de 1993 y su paquete de normas que permite la enajenación de tierras comunales; además, sería bastante más complicado si la comunidad tuviese saneada su propiedad e inscrita en registros públicos. ${ }^{20}$

Los directivos de la Junta Directiva Comunal sJBC (2017-2018) señalan que, entre los años 2006 y 2011, directivos corruptos habrían vendido a inversionistas privados un total de 10000 hectáreas de la comunidad de manera ilegal — sin consulta ni Asamblea de Comuneros-, utilizando la figura anteriormente descrita. Aunque no las han ocupado aún, estos han conseguido titular esas tierras como suyas, dividirlas en varios lotes y transferirlas a nuevos propietarios, con lo cual se hace muy complicado para los comuneros rastrear el proceso. ${ }^{21}$ Legalmente, esas tierras no le pertenecen más a la comunidad; es una trampa de la que difícilmente las nuevas directivas podrán salir. Todo ello
${ }^{19}$ Fragmento de comunicación telefónica personal de la autora con la dirigente de la asociación de moradores de Santa Rosa a los tres días del desborde del río Piura del 2017. Su nombre ha sido omitido por seguridad.

${ }^{20}$ Este mecanismo ha sido reconstruido en base a numerosas entrevistas con directivos de la comunidad y a la revisión de documentación de registros públicos.

${ }^{21}$ Fuente: entrevista al presidente del Frente de Defensa de las Tierras de Cura Mori (2016); entrevista al asesor técnico de la comunidad (2016). Reunión con la Junta Directiva de la Comunidad período 2017-2018.

\section{territarias 42-Especial}




\section{tersitorias \\ 42-Especial}

Figura 3. Área lotizada por empresas agroindustriales en una zona del territorio comunal ancestral de la comunidad SJBC

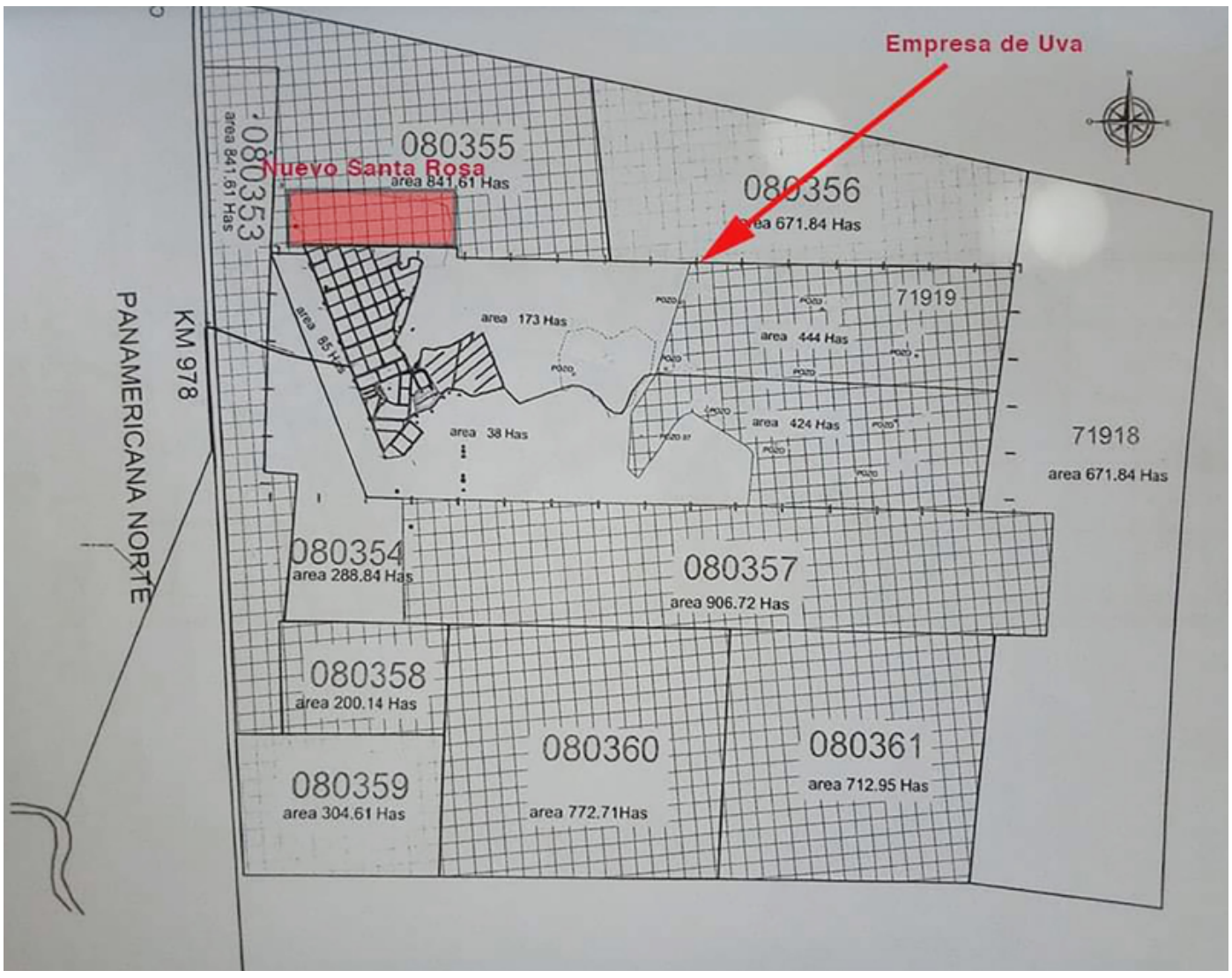

Nota: El polígono pequeño indica la ubicación del asentamiento Nuevo Santa Rosa.

Fuente: planos proporcionados por la directiva comunal a la arquitecta Rocío Álvarez (2017).

deslegitima a la institución comunal frente a los comuneros que ya estaban alejados de su aparato político-institucional.

Con lo anterior, los comuneros reasentados en el descampado luego del desborde del río se enfrentaban a dos conflictos: (i) el limítrofe con la empresa de uva ya instalada, que data del año 2013 , y (ii) con los "nuevos dueños de la tierras", que se apropiaron de miles de hectáreas de la comunidad, dentro de las cuales se encuentran las tierras que esta había cedido tanto a los moradores de Santa Rosa como a otros cientos de comuneros de caseríos vecinos y, que en el contexto de la emergencia, requieren ocupar. 
Así, luego del desborde del río, más de 1300 familias del conjunto de caseríos reasentados, ubicadas en siete nuevos asentamientos en el desierto, ${ }^{22}$ se encontraron de pronto en una situación de extrema vulnerabilidad: sin cultivos ni agua ni casas se redujo aún más su capacidad para resistir al avance de las empresas. La nueva prioridad para todas ellas fue reorganizarse y conseguir que el Estado apruebe sus pedidos de vivienda y servicios básicos para iniciar una nueva vida. Ante la lentitud de la respuesta estatal, la empresa de uva encontró un espacio para entablar nuevas relaciones con los moradores. A lo anterior se suma el distanciamiento en los últimos años entre el aparato del gobierno comunal y los comuneros, en particular jóvenes que ya no participan de la vida comunera (asistencia a asambleas, etc.). Todo ello dio espacio a que surgieran nuevas estrategias para convertir el nuevo asentamiento en un espacio de vida, que no incluyen a la comunidad como referente institucional.

Aunque en la carátula de la agenda política de la Junta Directiva de la comunidad (2017-2018) se lee "Continuaremos la reivindicación de nuestras tierras usurpadas por los nuevos gamonales", lejos del local comunal, en el descampado, los nuevos líderes, quienes ya no guardan relación formal con el gobierno comunal, continúan gestionando el día a día de los asentamientos con el personal de relaciones comunitarias de la agroindustria vecina. En la dinámica de las negociaciones cotidianas necesarias para la supervivencia en el desierto, la comunidad no está presente. De esta forma, esta va siendo desplazada poco a poco de la organización de Nuevo Santa Rosa.

\section{Nuevas técnicas territoriales y narrativas en el contexto de la emergencia: de comuneros posesionarios a una población en emergencia}

A comienzos del reasentamiento en marzo del 2017, tanto el Frente de Defensa de las tierras de Cura Mori —que aún sobrevivía-, como algunos - aunque pocos- jóvenes dirigentes de los caseríos afectados desplegaron un discurso que se fundaba en los derechos ancestrales de la comunidad sobre el territorio. En un primer momento, esta narrativa constituyó el argumento principal de la comunidad y del Frente para presentarse ante el gobierno regional, señalando la ocupación de las empresas como ilegítima. Sin embargo, el propio Estado peruano, a través del gobierno regional y el Ministerio de Vivienda, invalidó sus argumentos: sin un título de propiedad a nombre de la comunidad, esta no era propietaria de estas tierras y, por ende, no tenía facultad de cederlas a sus comuneros.

Para completar el escenario descrito, es importante señalar que el Estado peruano propuso una zona de reasentamiento posdesastre para la población de todos los caseríos afectados. La propuesta fue elaborada por el Ministerio de Vivienda a
${ }^{22}$ A dos meses del desastre, Humanitarian Response de Naciones Unidades registró 1339 familias (6531 personas) en los siete albergues que se encuentran en los nuevos asentamientos a lo largo del kilómetro 980 de la antigua carretera $\mathrm{Pa}$ namericana, sobre tierras que legalmente tienen nuevos propietarios privados (www.humanitarianresponse.info/en/operations/ peru/infographic).

\section{territarios 42-Especial}

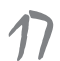


${ }^{23}$ La información sobre "Una sola Fuerza (Piura)" es oficial y fue proporcionada por dirigentes de Nuevo Santa Rosa.

${ }^{24}$ Fragmento de entrevista a dirigente de Nuevo Santa Rosa sobre su reunión con el viceministro de vivienda en el año 2017. Su nombre ha sido omitido por seguridad.

${ }^{25}$ El informe de Humanitarian Response (2017) señala: "706200 personas con afectación en medios de vida, en zonas rurales y urbanasen la Costa Norte peruana. La mayoría de las zonas afectadas, especialmente en Piura, presentan una situación crítica debido a la acumulación de aguas y lodos contaminados, basura, escombros y otros residuos que impiden la entrega bumanitaria, movilidad de las personas, la provisión y acceso a servicios básicos, acceso a los mercados para abastecimiento de comida, lo que está deteriorando rápidamente la calidad de vida de las familias y poniendo en grave riesgo su salud. Se debe notar además que la emergencia ba tenido lugar en zonas con altos niveles previos de fragilidady vulnerabilidad por pobreza multidimensional que ha

territarios 42-Especial través del proyecto habitacional Una sola Fuerza. Este consideraba un área de tan solo 20 hectáreas en un distrito al noroeste de la ciudad de Piura, lejos de los antiguos caseríos y de las tierras agrícolas. En el caso de Santa Rosa de Cura Mori, a 26 kilómetros del antiguo caserío — donde se ubican la mayoría de parcelas - y a 27 kilómetros de Nuevo Santa Rosa (figura 4). Los lotes para cada familia iban a ser de $62,5 \mathrm{~m}^{2}$ y se estimaba la entrega de 2000 viviendas. ${ }^{23}$ La propuesta estatal generó malestar entre la población, no solo por la ubicación, sino también por no considerar áreas para crianza de animales de corral. Los pobladores de Nuevo Santa Rosa y demás caseríos afectados decidieron permanecer en las tierras del descampado cercanas a la carretera Panamericana que les había entregado años atrás la comunidad, haciendo uso de su derecho de comuneros en posesión. El siguiente fragmento, en el que un comunero relata su encuentro con un alto funcionario del Estado, expresa la distancia entre la lógica del proyecto estatal y las expectativas de las familias comuneras:

Nos decían: "son traficantes, por qué mucha área quieres, seguro para que vendas (...)". Nosotros les dijimos: "somos campesinos, nosotros criamos nuestras cabras, hacemos un montón de cosas, tenemos una casa, un huerto".24

$\mathrm{Al}$ igual que en la cita anterior, en reiterados intentos por acercarse a diferentes entidades estatales, los moradores de Nuevo Santa Rosa fueron recibidos como víctimas humanitarias, pero no cuando se presentaron como comuneros reclamando derechos territoriales. Frente a esta situación, los nuevos liderazgos tomaron una postura más pragmática y asumieron la negociación de un grupo de moradores con la empresa de uva las tierras comunales.

Pasados los meses, enfrentando condiciones extremas, sin servicios básicos y muchas veces sin ningún ingreso, las familias se encontraban en situación incierta. ${ }^{25}$ Algunos empezaron el retorno al viejo caserío, en donde las aguas del río ya han bajado. En este contexto, el discurso de reivindicación comunero no resulta funcional en las negociaciones con la empresa de uva ni con el Estado. Frente a las presiones de la empresa - incluyendo amenazas directas a dirigentes mujeres de la zona, ofrecimientos de beneficios a la población y denuncias judiciales a líderes locales-, se tuvo que recurrir a una nueva narrativa que permitiera a los dirigentes entrar en un nuevo registro para la negociación. Poco a poco, los nuevos liderazgos que se consolidaron en el contexto de la emergencia lograron canalizar ayuda humanitaria y proyectos de ONG, movilizaron el dispositivo del desastre y de la crisis humanitaria para justificar sus demandas en el gobierno regional, y desactivaron el dispositivo de la lucha comunera.

Así, tras la emergencia climática, coexistían en la comunidad dos registros discursivos. Lo anterior se evidencia en 
Figura 4. Antiguo caserío Santa Rosa de Cura Mori, asentamiento Nuevo Santa Rosa, y zona propuesta por el Estado para el proyecto habitacional de reubicación "Una Sola Fuerza" rechazado por los comuneros

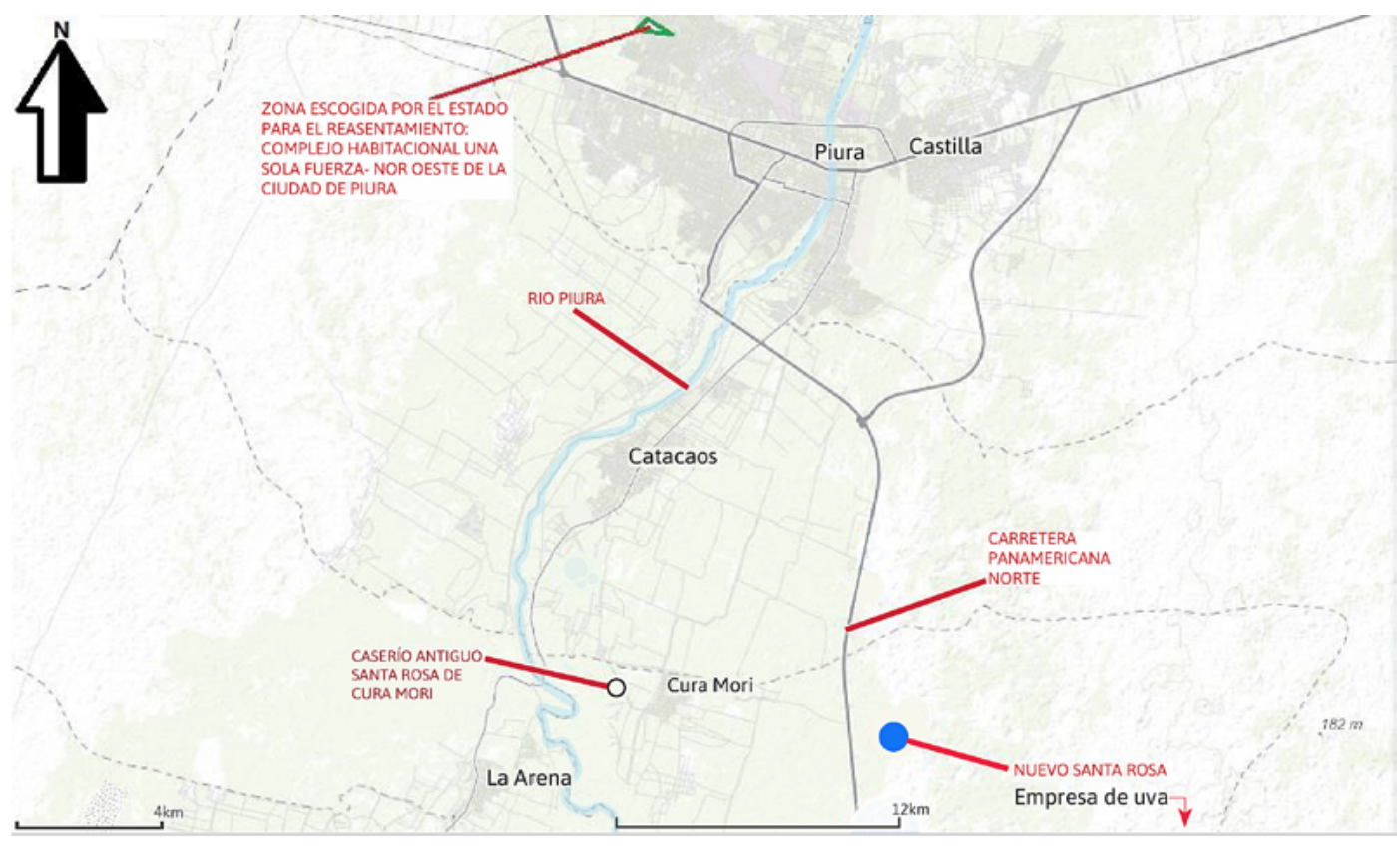

Fuente: Humanitarian Response (2018). Las líneas rojas han sido añadidas por la autora.

el siguiente ejemplo: la dirigente de 38 años, quien en ese momento era la primera presidenta de la asociación de moradores del caserío de Santa Rosa, apelaba al pasado y a la legitimidad de la comunidad para alegar derechos ancestrales sobre el territorio. Aunque no pertenece a las viejas generaciones, ella recurre a la memoria de luchas de la comunidad y habla de lo que "les ha costado a sus abuelos tener esas tierras". Acusada por la empresa de uva de usurpación de tierras, la dirigente requería un abogado para su defensa que la comunidad no le pudo proporcionar. En paralelo, otro dirigente del asentamiento Nuevo Santa Rosa, de 44 años, decidió negociar las tierras con la empresa a cambio de beneficios concretos: se mueve en el registro de la crisis humanitaria y transita con facilidad por las instancias del Estado y por las ONG que han llegado a la zona, logrando canalizar pequeños proyectos de la cooperación internacional. ${ }^{26}$ Todo ello generó que la dirigente dejara el cargo y que, al igual que un grupo de familias, optara por retornar al antiguo caserío enfrentándose al azar de un posible nuevo desborde del río. Las familias que acentuado los efectos sobre la población, especialmente dada la prevalencia de la economía informal y producción de subsistencia”.

${ }^{26}$ Los nombres de los dirigentes se han omitido intencionalmente por motivos de seguridad. 


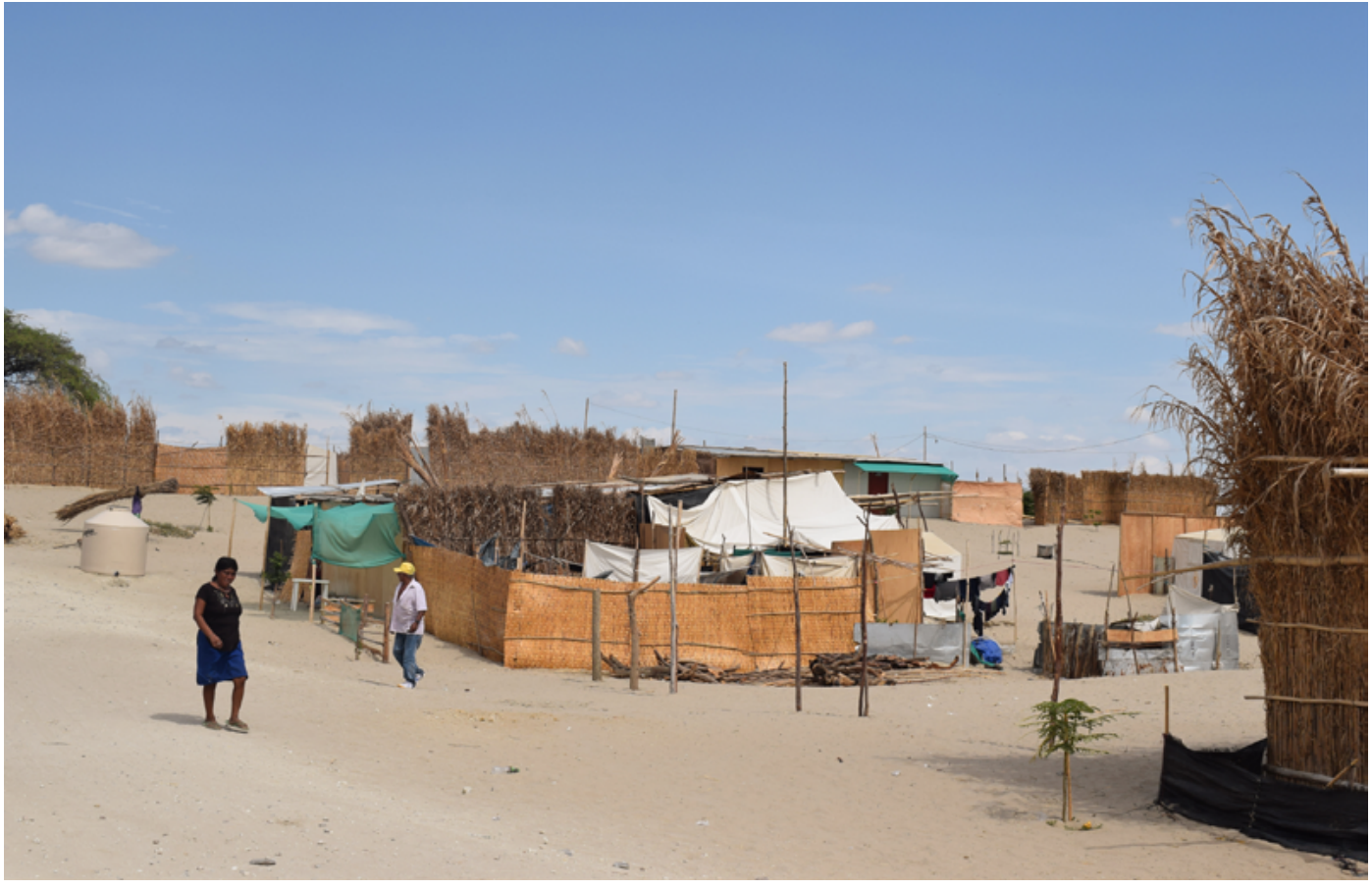

Fuente: M. Burneo, marzo de 2018 (a un año del desborde del Río).

optaron por quedarse definitivamente en el descampado, junto a otros seis asentamientos vecinos, apoyan a su nuevo dirigente, quien tiene un vínculo fluido con la empresa de uva. Además, este logró que los "nuevos dueños de la tierra" le cedan a Nuevo Santa Rosa una superficie de 47 hectáreas para la lotización de viviendas de 30 metros por 10 metros y algunas pequeñas áreas comunes para la escuela y otros servicios proyectados como el comedor popular (figura 5).

Lejos de una lógica de bienes comunes, en este proceso la técnica de ocupación de las tierras del descampado pasa a ser la lotización, que consiste en el reparto de cuadrículas de 300 metros cuadrados a las familias comuneras reasentadas. Traída de la experiencia previa de cientos de asentamientos humanos formados en la región Piura - y en el Perú, en general- durante el siglo pasado, la lotización o el reparto de lotes con una lógica urbana ha sido el modo privilegiado de formación de nuevos asentamientos en las periferias de las ciudades. En este caso, la lotización solo consideró áreas de vivienda, mas no áreas productivas. Así, los dirigentes de Nuevo 
Santa Rosa han logrado asegurar las nuevas zonas de vivienda, renunciando a la lucha por la reivindicación sobre las extensas tierras comunales del bosque seco.

Respecto a las 10000 hectáreas que fueron compradas por inversionistas privados, los antiguos dirigentes de la comunidad de Catacaos saben que será muy difícil su recuperación luego de todo lo ocurrido en este tiempo en el que el territorio se ha reconfigurado de manera violenta. Los actuales directivos de la comunidad reconocen que no solo se han perdido las tierras, sino que también se ha mermado su legitimidad como defensora del territorio comunal. Las ambigüedades y contradicciones que surgen entre los comuneros y su relación con la institución comunal se observan en las dinámicas cotidianas y en el desarrollo de microtensiones y conflictos, así como en los nuevos vínculos que se tejen entre ellos y los agentes privados sin tener como instancia intermediaria a la comunidad. En el ámbito de los nuevos asentamientos del desierto, las antiguas categorías sobre las que se fundaba la identidad comunera fueron desplazadas poco a poco: tópicos como defensa de la tierra, lucha contra los nuevos gamonales y comunidad "autónoma e indestructible" desaparecieron del discurso de los nuevos liderazgos. Para los antiguos comuneros, esta evolución constituye una traición a la comunidad; para los nuevos líderes, menores de cincuenta años, se trata de lograr —en sus propios términos- “el progreso del pueblo" y asegurar al menos un espacio de vivienda para las futuras generaciones que muy probablemente ya no se dedicarán a la tierra.

\section{Nuevos tiempos y actores: técnicas territoriales de las empresas agroindustriales}

Los empresarios han minado el frente de defensa; les han dado trabajo y se acabó la lucha. Ellos eran combativos [los comuneros] pero ahora se voltearon. Asi hemos perdido las zonas de pastoreo, sin esas miles de hectáreas del bosque ya no se puede hacer ganadería comunal. ${ }^{27}$

Estudios como el de Anaïs Marshall (2014), sobre los efectos del avance de las grandes inversiones privadas en los cambios de usos del suelo en dos zonas de la costa peruana, o como el de Mesclier, Auquier y Vaillant (2014), sobre la desigualdad en el acceso a recursos en comunidades de la costa norte en el contexto de la globalización, muestran cómo las normas estatales dan cabida a que las empresas obtengan agua a la que otros no pueden acceder y también "permiten" (sin regular) que estas empresas utilicen toda el agua que quieran sin tener en cuenta la capacidad hídrica del lugar, secando valles enteros (Marshall, 2014). Para el caso de Piura, van der Ploeg (2006) se refiere a las empresas agroindustriales en territorios comunales del bosque seco como "Imperio". Se trata de una forma particular de extracción de recursos en la que Imperio se
${ }^{27}$ Fragmento de entrevista al asesor de la Junta Directiva de la comunidad campesina, sobre la situación de las tierras y la negociación entre pobladores de Nuevo Santa Rosa y la agroindustria (octubre de 2017). territarios 42-Especial 21 
${ }^{28}$ Este problema se evidencia en las cifras de comunidades no tituladas registradas en el SICCAM (Sistema de Información de Comunidades Campesinas del Perú) formulado por el Centro Peruano de Estudios Sociales (CEPES) y el Instituto del Bien Común (IBC) (bttp:// www.ibcperu.org/mapas/ siccam/). Asimismo, es uno de los temas clave de la "Agenda para el Buen Vivir" (2018) publicada por el Pacto de Unidad de Organizaciones Indigenas del Perú, organización de segundo nivel reconocida por el Estado peruano, que articula a las principales organizaciones indigenas y campesinas nacionales.

\section{territorias 42-Especial}

instala en un territorio y lo usa hasta agotar sus capacidades sin generar dinámicas de desarrollo en la zona: Imperio deja el suelo infértil y seca los ojos de agua en el desierto a los que accede con su tecnología de punta (van der Ploeg, 2006).

En la costa, las agroindustrias utilizan el agua del subsuelo que obtienen con pozos tubulares; en el caso específico de los nuevos asentamientos del bosque seco de Catacaos, la empresa de uva utiliza este recurso no solo para su producción, sino también como un elemento de negociación: en medio de la crisis humanitaria, la agroindustria ofreció abastecer de agua a los comuneros del asentamiento Nuevo Santa Rosa a cambio de que abandonen a la comunidad en la lucha por recuperar las tierras de las que se había apropiado. La agroindustria utiliza distintas técnicas y mecanismos para acceder a tierras del bosque seco, legitimar sus prácticas y controlar el espacio. Estas, comunes a más de una empresa, consisten en un conjunto de mecanismos legales y dispositivos administrativos y jurídicos, que se despliegan en paralelo a estrategias coercitivas y de clientelismo, que aprovechan un contexto marcado por la debilidad institucional de la comunidad y la vulnerabilidad de las familias en un contexto de emergencia.

\section{Normas y dispositivos juridicos $y$ administrativos del despojo}

Las normas sobre tierras que se desprenden de las reformas neoliberales en el
Perú brindan el marco legal para que los empresarios privados accedan a este recurso: desde la eliminación de la condición de inalienables e inembargables de las tierras comunales (Constitución de 1993 ) hasta un conjunto de leyes como la Ley de Tierras 26505 de 1995, que dio paso a que las comunidades de costa puedan decidir la parcelación y venta de sus tierras si así lo aprobaba la mitad más uno de los presentes en la Asamblea General de Comuneros (Castillo, 2009; CEPES, 2009). En el caso de los mecanismos jurídicos y administrativos, un claro ejemplo es el de los títulos de propiedad comunal nunca inscritos en los registros públicos, mecanismo que ha sido documentado (Diez, 2017; Burneo, 2013; 2016a) y que es un problema reconocido por entidades especializadas y las propias organizaciones nacionales campesinas y de pueblos originarios. ${ }^{28}$

Los empresarios han aprendido que las antiguas comunidades de la costa, si bien tienen títulos anteriores a la formación del Estado republicano, adolecen de un catastro culminado y de títulos del conjunto del territorio comunal inscritos en los registros públicos. Asimismo, saben que los proyectos especiales de titulación de tierras, financiados por el Banco Interamericano de Desarrollo, en su primera fase (PETRTl, 1993-2000) y segunda fase (PETRT2, 2000-2006), titularon predios de tenencia individual de comuneros posesionarios como propiedad privada al interior de territorios comunales 
sin aprobación de la Asamblea. ${ }^{29}$ Ello abre al menos tres caminos para apropiarse de terrenos de la comunidad: i) la compra ilegal de tierras comunales de zonas del descampado; ii) el denuncio de tierras del bosque seco "en abandono", argumentando su posesión para inversión y posterior inscripción en registros públicos, y iii) la compra legal pero ilegítima de tierras a pequeños agricultores comuneros (o excomuneros) que recibieron títulos individuales de propiedad al interior del territorio comunal.

Lo anterior muestra el uso de mecanismos de apropiación territorial producto de un aprendizaje corporativo de las ventajas, pero también de los vacíos y ambigüedades de la legislación peruana en materia de tierras, sin olvidar el problema de superposición de derechos (privado/ comunal) que generó la titulación de tierras y sus irregularidades, entre 1995 y 2005. Los empresarios también han aprendido que ni el gobierno regional ni el nacional abogará por las comunidades y que estas se encuentran en una posición débil frente al mismo Estado.

\section{Técnicas territoriales de control, coerción y clientelismo ${ }^{30}$}

A un mes de la emergencia, asentados en el desierto en carpas donadas, sin agua ni luz y a tres horas de distancia a pie de su viejo caserío, las familias se encontraban en situación de alta vulnerabilidad. En este contexto, y ante el afianzamiento de nuevos liderazgos en el asentamiento Nuevo Santa Rosa, la empresa se acercó a negociar. Para ello utilizó un recurso escaso en la zona al que tenía acceso gracias a los permisos otorgados por el Estado: el agua. La empresa ofreció a los moradores del asentamiento puestos laborales, módulos de triplay para construir viviendas y llenarles el tanque de agua que les había donado una ONG, que no tenían cómo abastecer.

Con el tiempo, la presencia de la empresa en el nuevo asentamiento, a través de su personal de relaciones comunitarias, se volvió constante: acompañan a los dirigentes del asentamiento a realizar trámites en la municipalidad, financian eventos festivos (como la chocolatada navideña) y donan útiles escolares para los niños, entre otras acciones. A un año del desborde del río, en marzo de 2018, la situación era la siguiente: los módulos de vivienda ofrecidos por la empresa no se habían construido, esta dio tan solo diez puestos de trabajo rotativos como guardias de seguridad a los moradores de Nuevo Santa Rosa y, en efecto, continuaba abasteciendo de agua el tanque del cual dependen las familias del asentamiento para sobrevivir en el desierto.

Lo ocurrido en este caso muestra una figura inédita que revela mucho de los procesos de cambio en las lógicas comunales y de cambio institucional: un grupo de comuneros posesionarios pero no propietarios cede una porción entera del territorio de la comunidad sin permiso de
${ }^{29}$ Este es un tema conflictivo en el Perú, trabajado por ejemplo por Monge (2004) y del Castillo, Castillo y Márquez (2011), y es tema de agenda del Grupo de Trabajo de Pueblos Indigenas del Ministerio de Cultura. El desembolso del préstamo del BID para la tercera etapa de titulación de tierras (PTRT3) se oficializó en 2015 y está en curso.

${ }^{30}$ Estoy utilizando el término clientelismo en un sentido amplio, que no considera necesariamente el elemento partidario, pero sí político para referirse a un sistema (no formal) de lealtades asimétricas de intercambio de recursos entre alguien que otorga beneficios a cambio de apoyo politico para mantenerse en el poder, que supone intercambios no aislados sino relativamente estables en un periodo ( $Z a$ pata, 2016).

\section{territarias 42-Especial}

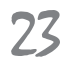


Tabla 1. Técnicas territoriales utilizadas por inversionistas privados y corporaciones

\begin{tabular}{|l|l|l|}
\hline \multicolumn{1}{|c|}{ Tipo de técnica } & \multicolumn{1}{|c|}{ Forma de despliegue } & \multicolumn{1}{c|}{ Efectos sociopolíticos } \\
\hline $\begin{array}{l}\text { Dispositivos } \\
\text { jurídicos y } \\
\text { administrativos } \\
\text { para el despojo }\end{array}$ & $\begin{array}{l}\text { Compra de predios en cesión } \\
\text { de uso a comuneros } \\
\text { Inscripción en registros } \\
\text { Judicialización a dirigentes }\end{array}$ & $\begin{array}{l}\text { Nuevos dueños con título } \\
\text { Inseguridad de comuneros } \\
\text { Menor control comunal } \\
\text { Repliegue de dirigentes enjuiciados } \\
\text { Quiebre del Frente de Defensa }\end{array}$ \\
\hline $\begin{array}{l}\text { Técnicas territoriales } \\
\text { de control del } \\
\text { espacio }\end{array}$ & $\begin{array}{l}\text { Marcar el espacio: cercos físicos } \\
\text { Violencia física: hombres armados } \\
\text { Uso de fuerzas del orden enviadas } \\
\text { por el Estado a pedido de la empresa }\end{array}$ & $\begin{array}{l}\text { Pérdida de acceso a zonas del bosque } \\
\text { seco de tránsito y uso común } \\
\text { Restricción de movilidad en el espacio } \\
\text { Repliegue de dirigentes amenazados }\end{array}$ \\
\hline $\begin{array}{l}\text { Técnicas clientelistas: } \\
\text { intercambio de } \\
\text { recursos para } \\
\text { sobrevivir en } \\
\text { el desierto }\end{array}$ & $\begin{array}{l}\text { Ofrecimiento de empleos, } \\
\text { módulos de vivienda y, sobre } \\
\text { todo, abastecimiento de agua } \\
\text { Intermediación ante } \\
\text { agentes externos }\end{array}$ & $\begin{array}{l}\text { Ruptura de asociación de moradores de } \\
\text { Nuevo Santa Rosa con la comunidad } \\
\text { Quiebre del Frente de Defensa } \\
\text { Reconfiguración de la organización en } \\
\text { función de intereses individuales } \\
\text { Nuevas lealtades acompañadas } \\
\text { de nuevas narrativas }\end{array}$ \\
\hline
\end{tabular}

Fuente: trabajo de campo en distintos momentos de los años 2016, 2017 y 2018.

la Directiva Comunal ni aprobación de la Asamblea a una empresa privada, a cambio de agua y algunos pocos puestos de trabajo (tabla 1). Ante ello, no hay capacidad de respuesta de la comunidad ni sus directivos, que no son vistos por el Estado como un actor legítimo para planificar las acciones de reconstrucción luego de la emergencia y que se ven desbordados por la realidad. Todo lo anterior no se explica solo por el contexto del desastre, sino también como efecto a mediado plazo de tres décadas de reformas políticas en el Perú, que derivaron en la desprotección de territorios comunales y en la promoción del modelo extractivo y agroexportador (Bebbington, 2007; CEPES, 2009).
Lejos quedaron los tiempos de los comuneros combativos de la heroica comunidad "autónoma e indestructible" - como rezan las letras a la entrada del local comunal en el pueblo de Catacaos-. La trasgresión de las normas comunales según las cuales las tierras del bosque seco son "de todos" significa una ruptura importante en una larga historia. En cierto sentido, abandonar la lucha comunera es también una salida para dejar de ser clasificados bajo la peligrosa etiqueta de usurpadores. Este tránsito de narrativas expresa una historia de cambios en los territorios comunales en cincuenta años: de la lucha por la tierra contra las haciendas, pasando por la formación de 
cooperativas y unidades comunales de producción durante la reforma agraria, a la tenencia individual y fragmentación de la tierra en el contexto neoliberal.

\section{Conclusiones}

El contexto de la emergencia y del desastre humanitario generados por el fenómeno El Niño Costero del 2017 es al mismo tiempo un caso de estudio para el análisis de los procesos recientes del bosque seco y una metáfora: no solo se desbordaron las aguas del río, sino también una compleja situación de superposición de derechos, la cual estalló evidenciando la debilidad institucional de la comunidad y la pérdida de su vínculo cotidiano con los comuneros, sobre todo con las nuevas generaciones.

A lo largo de estas páginas he analizado el despliegue de un conjunto de saberes territoriales tradicionales y mostrado cómo estos han sido desplazados por técnicas territoriales aplicadas tanto por las empresas como por los nuevos dirigentes de los asentamientos formados en el descampado. Estos movilizan un nuevo registro, tanto en sus formas de acción política, como en su práctica discursiva, para entrar en la lógica de la negociación con el Estado y con los nuevos agentes privados que poseen la tierra. Lo hacen en una búsqueda legítima no solo de sobrevivir en el desierto, sino de hallar un camino alternativo al de ser pequeños agricultores en crisis, sin acceso a crédito y con minúsculas parcelas que no superan las 0,25 hectáreas.

Asimismo, he discutido cómo se despliegan dos registros discursivos distintos: por un lado, el de la lucha comunal y, por otro, el de la vulnerabilidad o de la población en emergencia. Las implicancias en términos de la política local no son menores: debilitamiento de la relación entre comunidad y familias comuneras, pérdida de importancia de antiguos dirigentes, desactivación de organizaciones vinculadas a la comunidad (como el Frente de Defensa de las Tierras de Cura Mori), pérdida de poder de los pocos jóvenes dirigentes cercanos a la comunidad e instalación de un nuevo discurso proempresas agroindustriales entre ciertos sectores de comuneros.

Las nuevas técnicas territoriales se despliegan ante la ausencia de planificación y de recursos previos; la figura de la lotización del descampado anuncia el fin del bosque seco como espacio comunal. Es decir, esta técnica de ocupación territorial actúa como un dispositivo de distribución y fragmentación espacial, pero a la vez, irrumpe en la lógica de los bienes comunales que van reduciéndose y desapareciendo progresivamente para dar paso a una lógica individual y de ocupación urbana.

Finalmente, la narrativa que se ha desplegado a lo largo de esta reconfiguración territorial apela al dispositivo de la crisis humanitaria, que ha tomado el lugar de territarios 42-Especial 
las viejas consignas - mantenidas solo por pocos comuneros y por las dirigencias de la central comunal- Poco a poco, se ha normalizado el trato cotidiano de favores e intercambios entre nuevos líderes locales y personal de la empresa. Ello tiene una implicancia política y simbólica mayor: en la historia reciente de esta parte del bosque seco, los comuneros han pasado de ser luchadores por la tierra a ser "una población en emergencia". La población en emergencia solicita ayuda, pero no reclama derechos sobre el territorio ancestral. Un número importante de ella, hombres y mujeres, trabajan en los campos de uva como peones asalariados bajo condiciones que ellos mismos reconocen como de explotación (pero ese es otro tema). En suma, con el proceso de reasentamiento, la comunidad de Catacaos ha perdido bases de comuneros que ya no están articulados a las dinámicas políticas comunales.

\section{Referencias}

Bebbington, A. (2013). Industrias extractivas, conflicto social y dinámicas institucionales en la región andina. Lima: IEP-CEPES-GPC.

Bebbington, A. (Ed.). (2007). Mineria, movimientos sociales y respuestas campesinas. Una ecología politica de transformaciones territoriales. Lima: IEP-CEPES.

Burga M., \& Manrique, N. (1990). Rasgos fundamentales de la historia agraria peruana, ss. XVI-XX. En A. Chirif,
N. Manrique \& B. Quijandría (Eds.), Perú: el problema agrario en debate. SEPIA III (pp. 23-62). Lima: SEPIA.

Bury, J. (2007). Neoliberalismo, minería y cambios rurales en Cajamarca. En A. Bebbington (Ed.), Minería, movimientos sociales y respuestas campesinas. Una ecologia politica de transformaciones territoriales (pp. 49-80). Lima: IEP-CEPES.

Burneo, M. L. (2013). Elementos para volver a pensar lo comunal: nuevas formas de acceso a la tierra y presión sobre el recurso en las comunidades campesinas de Colán y Catacaos. Anthropológica, (31), 15-42.

Burneo, M. L. (2016a). Transformation de l'espace et privatisation des ressources communautaires au Pérou. Cahiers des Amériques Latines, (81), 53-72. https://www.doi.org/10.4000/ cal. 4273

Burneo, M. L. (2016b). Transformaciones en el gobierno del espacio comunal: decisiones y dinámicas políticas en torno a los usos de la tierra y la extracción de recursos en el caso de la comunidad San Lucas de Colán. SEPIA. Perú: El problema agrario en debate, 16, 327385. Recuperado de https://sepia.org. pe/wp-content/uploads/2018/07/ SEPIA-XVI-Arequipa-2016.pdf

Burneo, M. L., \& Huamán, A. (2013). Lógicas privadas y lógicas locales, una mirada a la presencia de las industrias extractivas desde las historias comunales. Politai, 4(6), 75-87. Recuperado 
de http://revistas.pucp.edu.pe/index. $\mathrm{php} /$ politai/article/view/14115

Castillo, M. (1991). Tierra y agua en las UCP: Catacaos. Diagnóstico agroecológico de la comunidad campesina San Juan Bautista de Catacaos, Bajo Piura. (Documento de trabajo mimeografiado, CIPCA-CCSJBC, Piura).

Castillo, P. (2009). El derecho a la tierra y los acuerdos internacionales: el caso del Perú. Lima: CEPES - Land Coalition.

del Castillo, L., Castillo, P., \& Márquez, J. (2011). Politicas públicas aplicadas a las comunidades campesinas. Segundo informe 2010. Lima: Grupo ALLPA.

Cenagro. (2012). Censo Nacional Agropecuario. Lima: INEI.

Centro Peruano de Estudios Sociales - CEPES-. (2009). La Revista Agraria. Especial: Concentración de la tierra, (107). Recuperado de https://larevistagraria. files.wordpress.com/2019/05/lra107_completo.pdf

Cruz Villegas, J. (1982). Catacaos. Origen y evolución histórica de Catacaos. Lima: CIPCA.

Dammert, J. L. (2016). Hacia una economía de la palma aceitera en el Perú. Lima: Oxfam.

Diez, A. (2006). Los problemas del poder: política local y gobierno en las reducciones de la costa de Piura, siglo XVII. Anthropológica, 24(24), 107-127.

Diez, A. (2012). Gobierno comunal: entre la propiedad y el control territorial. El caso de la comunidad de Catacaos. Sepia. Peru: el problema agrario del debate, 14, 115-148. Recuperado de https://sepia.org.pe/wp-content/ uploads $/ 2018 / 07 /$ SEPIA-XIV-Piura2011-Completo.pdf

Diez, A. (2017). Propiedad y territorio como (diferentes) bienes comunes. El caos de las tierras de comunidades en la costa norte peruana. Eutopia, (11), 1739. https://www.doi.org/10.17141/ eutopia.11.2017.2851

Directorio Nacional de Centros Poblados. (2017). En Censo Nacional de Población y Vivienda. Gobierno del Perú.

Eguren, F. (2004). Las políticas agrarias en la última década: una evaluación. Sepia. Perú: el problema agrario en debate, $X, 19-78$. Recuperado de https://sepia.org.pe/wp-content/ uploads/2018/07/SEPIA-X-PUCALLPA-2003.pdf

Eguren, F. (2009). La reforma agraria en el Perú. Debate Agrario. Análisis y alternativas, (44), 63-110.

Eguren, F. (2013). Acaparamiento de tierras. Reflexiones a partir de estudios de casos. Histoire(s) de l'Amérique latine, 8. Recuperado de http://www.hisal. org/revue/article/Luna2013-8b.

Escobar, A. (2014). Territorios de diferencia: la ontología política de los “derechos al territorio". En A. Escobar (Comp.), Sentipensar con la tierra. Nuevas lecturas sobre desarrollo, territorio y diferencia (pp. 67-132). Medellín: Ediciones UNAULA.

Göbel, B. (2015). Extractivismo y desigualdades sociales. Iberoamericana, territarios 42-Especial 


\section{tersitorios} 42-Especial
15(58), 161-165. https://www.doi. org/10.1844l/ibam

Göbel, B., Góngora, M., \& Ulloa, A. (Eds.). (2014). Desigualdades sociales en América Latina. Bogotá: IberoAmerikanisches Institut y Universidad Nacional de Colombia. Recuperado de http://209.177.156.169/libreria_cm/archivos/pdf_1391.pdf

Huamán, A. (2018). Tierras en pugna: cambios en la tenencia y el valor de la tierra comunal frente a la expansión del agronegocio del etanol en el valle del Chira, Piura: el caso de la comunidad campesina San Lucas de Colán. (Tesis de pregrado, Lima, PUCP).

Instituto del Bien Común - Centro Peruano de Estudios Sociales. Sistema de información sobre comunidades campesinas del Perú-SICCAM. Recuperado de https://ibcperu.org/mapas/siccam/

Le Roy, E. (2011). La terre de l'autre. Une anthropologie des régimes d'appropriation foncière. Paris: Lextebso Editions.

Marshall, A. (2014). Apropiarse del desierto: agricultura globalizada y dinámicas socioambientales en la costa peruana. El caso de los oasis de Virú e Ica-Villacuri. Lima: Instituto Francés de Estudios Andinos (IFEA).

Matos Mar, J., \& Mejía, J. (1980). La Reforma Agraria en el Perú. Lima: IEP.

Mazurek, H. (2009). Gobernabilidad y gobernanza en territorios de América Latina Actes \& Mémoires de l'Institut
Français d'Études Andines, 25. Recuperado de https://horizon.documentation.ird.fr/exl-doc/pleins_textes / divers13-03/010048116.pdf

Mesclier, E., \& Chaléard, J.L. (2006). Le paradoxe social des territoires gagnants: l'exemple de Motupe au Pérou. En J. Lombard, E. Mesclier \& S. Velu (Eds.), La mondialisation côté Sud: acteurs et territoires (pp. 373-388). Paris: IRD. http://www.doi.org/10.4000/books. irdeditions.6741

Mesclier, E., Auquier, C., \& Vaillant, M. (2014). Olmos, un verger dans le désert côtier péruvien. Inégalités d'accès à l'eau, systèmes de production agricole et nouvelles dynamiques dans la mondialisation. En Actes du colloque "Oasis dans la mondialisation : ruptures et continuités” (pp. 39-48). París.

Mesclier, E., Mamani, J., \& Huamantingo, A. (julio 2018). Generación de nuevos saberes territoriales en periferias disputadas: el caso de la comunidad campesina de Jicamarca (Lima, Perú). Ponencia presentada en el 56 Congreso Internacional de Americanistas. ICA-Salamanca.

Monge, C., et al. (2004). Las comunidades campesinas y los nuevos marcos institucionales. En A. Laos (Ed.), Las comunidades campesinas en el siglo XXI (pp. 65-68). Lima: ALLPA-CEPES.

Naciones Unidas, Humanitarian Response (2017). Flash Appeal-Costa Norte del Perú. 
Ostrom, E. (1990). Governing the commons. Nueva York: Cambridge University Press.

Pajuelo, R. (2000). Imágenes de la comunidad. Indígenas, campesinos y antropólogos en el Perú. En C. I. Degregori (Ed.), No hay país más diverso. Compendio de antropología peruana (pp. 123-179). Lima: PUCP, UP-IEP.

Van der Ploeg, J. D. (2006). Treinta años después, de vuelta a Catacaos. En El futuro robado. Tierra, agua y lucha campesina. Lima: IEP-Walir.

Perevolotski, A. (1991). Sistemas de producción caprina en Piura. Piura: CIPCA.

Remy, M. I. (2013). Historia de las comunidades indigenas y campesinas del Perú. Documento de trabajo 202, Lima: IEP.

Revesz, B. (1992). Catacaos: una comunidad en la modernidad. Debate Agrario, (14), 74-105.

Revesz, B., Aldana, S., Hurtado, L., \& Requena, J. (1996). Piura: región y sociedad. Derrotero bibliográfico. Cusco: CIPCA-CBC.

Urrutia, J. (2003). Cambios y permanencias comunales en medio siglo: revisita a un texto olvidado. Debate Agrario, (35), 183-194.

Zapata, A. (2002). Identificación de las vulnerabilidades sociales en las comunidades 26 de noviembre, anexo Santa Rosa, Eleuterio Cisneros y Nuevo Santa Rosa del Distrito de Cura Mori. Piura: Cipca.

Zapata Osorno, E. (2016). Clientelismo político. Un concepto difuso pero útil para el análisis de la política local. Estudios Políticos, 49, 167-185.

Zegarra, E. (2003). Mercado de tierras y desarrollo agrario en Perú: reflexiones en torno a una investigación. En P. Tejop (Comp.), Mercados de tierras agricolas en América Latina y el Caribe: una realidad incompleta (pp. 385-409). Santiago de Chile: CEPAL-GTZ. 